\title{
Un/Convention(al) Refugees: Contextualizing the Accounts of Refugees Facing Homophobic or Transphobic Persecution
}

\author{
SHARALYN R. JORDAN
}

\begin{abstract}
Propelled by fear of violence and flight from stigma, impelled by desire for connection and belonging, the movements of people whose sexualities or genders defy and offend norms cover a complex spatial, social, and psychological terrain. This paper presents partial findings of a critical qualitative inquiry conducted in partnership with Rainbow Refugee Committee, a community organization that supports and advocates with Queer, Lesbian, Gay, Bisexual, Trans (LGBTQ) and HIV-positive refugee claimants/migrants. This inquiry into how queer refugees engage in settlement comprised participation in Rainbow Refugee Committee and narrative interviews with LGBTQ refugee claimants and refugees, as well as interviews with service providers, community organizers, and lawyers. This paper explores how pre-settlement experiences conditioned possibilities for safety and belonging through refugee protection. While seeking refugee protection, queer refugees are evaluated against expected narratives of refugee flight and of LGBT identity. This paper reflects on the unconventionality of queer refugees' accounts in relation to these expectations. Queer refugees settling in Canada recounted surviving persecution by dis/avowing their desires, distancing/taking on available identities, avoiding/seeking out others, and conforming/escaping. They pursued mixed, often precarious, migration trajectories constrained by tightening migration controls and the relative obscurity of refugee protection for sexual or gender-based persecution. In their hearings, they struggled with and against Western cultural narratives of sexual and gender identities, coming out, and gender dysphoria. Interview excerpts highlight relational agencies in claimants' engagements with the refugee system.
\end{abstract}

\begin{abstract}
Propulsés par la crainte de la violence et la fuite de la stigmatisation, poussés par le désir de connexion et d'appartenance, les mouvements de personnes dont les sexualités ou les genres sont un défi ou une offense aux normes couvrent un terrain complexe spatial, social et psychologique. Cet article présente les résultats partiels d'une enquête critique qualitative menée en partenariat avec Rainbow Refugee Committee, un organisme communautaire qui soutient et défend les demandeurs d'asile/migrants lesbiennes, gays, bisexuels, transgenres, queer (LGBTQ) et séropositifs. Cette enquête sur la façon dont les réfugiés queer s'engagent dans la migration comprend des entretiens du Rainbow Refugee Committee et des interviews narratifs de l'auteur avec des demandeurs d'asile et des réfugiés LGBTQ ainsi que des entrevues avec des prestataires de services, organisateurs communautaires et avocats. L'auteure étudie comment les expériences pré-migratoires ont conditionné les possibilités en matière de sécurité et d'appartenance à travers la protection des réfugiés. En cherchant asile, les réfugiés queer sont évalués en fonction de récits attendus sur la fuite des réfugiés et l'identité LGBT. L'auteure offre une réflexion sur l'aspect non conventionnel des récits des réfugiés queer par rapport à ces attentes. Les réfugiés queer qui s'établissent au Canada disent avoir survécu à la persécution en dés/ avouant leurs désirs, en fuyant ou en revêtant des identités disponibles, en évitant ou en recherchant autrui, et en se conformant / s'échappant. Ils ont poursuivi des trajectoires migratoires mixtes, souvent précaires, contraints par le renforcement des contrôles migratoires et l'obscurité relative de la protection des réfugiés de la persécution en raison de leur sexe ou de leur genre. Dans leurs auditions, ils se sont battus avec et contre les discours culturels occidentaux sur les identités sexuelles et de genre, le coming out et la
\end{abstract}


dysphorie de genre. Des extraits d'entrevues mettent en évidence les intermédiaires relationnels dans les engagements des demandeurs d'asile avec le système des réfugiés.

C urrently no fewer than eighty countries criminalize same-sex sexual acts or gender "deviant" behaviour. ${ }^{1}$ Among these, five maintain the death penalty for male homosexual acts and four for sexual acts between women. Public morality laws are used to penalize samesex sexualities and gender variance. Laws prohibiting the "promotion of homosexuality" are used to inhibit political organizing. The existence of these laws creates a justification for violence and coercion against those whose appearance or behaviour transgresses sexual and gender norms. Protection from discrimination is not a right for queer, lesbian, gay, bisexual, and transgendered (LGBTQ) people in many parts of the world. ${ }^{2}$ Without this protection, groups are limited in their ability to organize, and people whose behaviour or appearance defies normative genders or sexualities are vulnerable. Legal statutes tell only some of the stories of homophobic and transphobic persecution. Pervasive social intolerance, compounded by lack of state protection, can make schools, neighbourhoods, faith communities, and families sites of violent persecution. Homophobic and transphobic persecution impel some LGBTQ people to move, leaving their homes, communities, and countries in an effort to create safety and belonging in their lives.

This paper presents part of a larger research project that traces and explores the intertwined psychological, spatial, and social trajectories of LGBTQ refugees settling in Vancouver, British Columbia, Canada. Refugees who have made claims based on sexual orientation or gender identity have lived in defiance of social erasure, stigma, and threatened or actual violence in their home countries. In migrating to Canada they have engaged with migration and border security systems that enable and restrict mobility based on the priorities of global capitalism and post-9/11 notions of security. Undertaking an asylum application entails accessing and working within a refugee system that was not designed with LGBTQ refugees in mind; requiring claimants to document an often hidden and stigmatized identity, and to disclose experiences, some traumatic, that are deeply private. In refugee hearings or interviews, applicants work with/against Western narratives of LGBT identities and coming out for recognition of their "membership in a particular social group," while their credibility is scrutinized. To settle, queer refugees negotiate belonging and exclusion within and across multiple communities: diasporic immigrant and co-national, LGBTQ, faith, and mainstream. In their defiance of oppressions, their engagement with the refugee system, and their quotidian work of settling, the efforts of LGBTQ refugees to build safety and belonging in their lives stretch the bounds of the possible.

Settlement is a long process, unfolding complexly over years. Possibilities for settling are shaped by experiences that precede and fall outside of "settlement" as defined by policy and practice. In this paper I draw on queer refugees' accounts of their experiences of their country-of-origin, migration, and the refugee application with a view to understanding how these shape and curtail possibilities for safety and belonging. Queer refugees' experiences living under persecution and during often complex, precarious migrations may work against their ability to be recognized as genuine refugees. The refugee system, implicitly and explicitly, evaluates applicants against expected trajectories of refugee flight and against Western narratives of LGBT identities, coming out, or gender identity dysphoria. Yet, for reasons and in ways explored in this paper, the migration trajectories and identity accounts of queer refugees may not meet these expectations. Having fled persecution, queer refugee claimants' potential for safety and belonging is constrained when they do not conform to conventions. By re-examining these assumptions in relation to knowledge constructed through refugee claimants' accounts, I aim to create alternative understandings of how the unconventional accounts of queer refugees make sense.

\section{Mode of Inquiry}

My research interest in queer migration has grown out of my volunteer work with two Vancouver-based community organizations that support and advocate with queer, lesbian, gay, bi, and trans migrants. I began volunteering with LEGIT: Canadian Immigration for Same-Sex Partners in 2000. In 1999 they supported my partner and me with an application for her permanent residency prior to the recognition of our relationship as family in Canada's immigration laws. LEGIT, along with EGALE and other legal advocates, played a central role in advocating for the recognition of same-sex partners in the Immigration and Refugee Protection Act enacted in 2002. ${ }^{3}$ By the mid-nineties LEGIT was fielding inquiries about asylum. To better address these issues, they formed Rainbow Refugee in 2000 to focus on advocacy and support for those facing persecution due to sexual orientation, gender identity, or HIV status.

I began volunteering with Rainbow Refugee in 2004. During drop-in meetings members who have completed the application process share experiences and answer questions for those beginning or engaged in the application process. As a volunteer with Rainbow Refugee I have witnessed and supported LGBTQ refugees' engagements with the refugee system and their efforts to rebuild lives in their new locale. This research grew out of recognition of the critical 
potential of their accounts to speak to a challenge that we were encountering in our community work, and that is articulated by queer migration scholar Eithne Luibheid in Queer/Migration: An Unruly Body of Scholarship.

Most scholarship, policymaking, service provision, activism, and cultural work remain organized around the premise that migrants are heterosexuals (or on their way to becoming so) and queers are citizens (even though second-class ones). Where do queer migrants figure in these frameworks and activities? ${ }^{4}$

Articulating a place for queer migrants entails exploring the complex interrelationships of queer sexualities and genders with migration. Towards this goal, queer migration scholars draw on a range of disciplines to pose questions, build theory, and produce knowledge with profound social justice implications. ${ }^{5}$ Two questions crystallize and mutually complicate queer migration research. Loosely, how is migration shaped by queer sexualities and genders; and how are queer sexualities and genders shaped by mobility and migration?

Queer migration scholars have begun to theorize how sexualities and genders become foci for asymmetrical power relations that constrain and enable mobility. ${ }^{6}$ Through the legacy of colonialism and the current practices of global capitalism, mobility has become highly skewed by a proliferation of policies, practices, and technologies that enhance the mobility of some, while exacerbating the immobility of others. ${ }^{7}$ In this context, how is the mobility of queer migrants co-constituted by the intersections of racialization, sexuality, gender, geopolitics, and class, among other factors? In this paper, I narrow this question further to explore ways that access to refugee protection in Canada is intersectionally constituted.

"Sexualities transmogrify in and of place." 8 Queer and feminist scholars have drawn attention to the situatedness of sexualities and genders. Tracing the genealogies of Western lesbian, gay, bisexual, ${ }^{9}$ and transgender ${ }^{10}$ identities has demonstrated the cultural specificity of LGBT identities and narratives of coming out or gender dysphoria. ${ }^{11}$ Medical, psychological, and popular discourses produced and promulgated the LGB coming out narrative. The narrative of gender dysphoria problematizes gender variance, making it intelligible as pathology, while simultaneously reifying binary gender. ${ }^{12}$ Both narratives, and the identities they constitute, rest on Western modernist notions of autonomous self, stability of identity, and categorical constructions of sexuality and gender. The coming out narrative and its construction of same-sex desire as a basis for both identity and community have spread transnationally. Similarly, the gender dysphoria narrative and the diagnosis of gender identity disorder have circulated, globalizing and reifying gender variance as pathology.

However, the transnational landscape of transgressive sexualities and genders that emerges with globalization is not a simple one of Western dominance. Interdisciplinary queer research is creating a picture of the sexual/gender cultures that are forming through interactions of local cultures and transnational queer networks. ${ }^{13}$ "Sexuality is indeed on the move," Michael Warner states in Queer Diasporas, not just because people are more on the move now than ever, but because non-normative sexualities may be enabled by the displacement of culture."14

When a practitioner of "homosexual acts," or a body that carries any of many queering marks moves between officially designated spaces-nation, region, metropole, neighborhood, or even culture, gender religion or disease-intricate realignments of identity, politics, and desire take place. ${ }^{15}$

The tensions, accommodations, resistance and interimbrication among coexisting local and global sexualities is explicated by a growing body of scholarship. ${ }^{16}$ Mobility gives rise to new practices, communities, and thus possibilities for identification. In offering new possibilities for identification, migration opens or undoes some identity boundaries, while potentially reinforcing others. ${ }^{17}$

Queer refugees are navigating complex psychological, social, and spatial identity terrains throughout their migration. The interactions of persecution, stigma, and erasure in shaping identity formation and complex migration trajectories are briefly explored. I then focus on two discourses that constitute inclusion/exclusion boundaries for accessing refugee protection: genuine refugee flight and LGBT identities. Drawing on participants' accounts provides a sense of their relational agencies in their engagements with these boundary discourses.

Problems inherent in interpreting the myriad ways that cultures organize and understand sexualities and genders through Western identity constructs like homosexual, transsexual, lesbian, gay, bisexual, transgender, or queer is at the crux of the struggle for queer refugee claimants, and yet to proceed we need some common language. I use queer to refer to diverse transgressive sexualities and genders produced through the intersectionality of practices, identities, and institutions in all cultures. ${ }^{18}$ At times I use LGBTQ to emphasize some of the heterogeneity that exists within queer. To delineate sexual orientation and gender identity when that is critical, I refer to queer sexualities and trans genders. Moving between queer, a term that accentuates the contested and socially constituted qualities of sexualities and genders, and LGBTQ, an acronym that holds both 
the contesting and the essentializing possibilities inherent in naming, is an imperfect approach to an irresolvable issue. The approach conveys some of my own struggle with and against the traditions of scholarship in my discipline, counselling psychology, and my efforts to be intelligible to a multidisciplinary audience of advocates, practitioners, policy makers, and scholars.

\section{Critical Qualitative Inquiry Process}

This paper presents findings from a critical qualitative inquiry ${ }^{19}$ conducted in collaboration with Rainbow Refugee Committee (RRC). For the study, three data generation strategies were used, each providing a different perspective on the research question, "How do queer refugees engage in settlement?" The first strategy entailed participant observation to generate my own experiential knowledge of queer refugee settlement. I continued participating in RRC and wrote reflexively about what I learned through these interactions. My involvement included twice-monthly drop-in meetings. I assisted and accompanied RRC members with pre-settlement tasks such as applying for legal aid and reporting for security checks. Rainbow Refugee members support each other through the hearing process, and as a volunteer I attended twenty hearings during the course of this research (20072009). My volunteer role also included organizing or participating in events including the Pride parade and service provider workshops. In 2010, I had the opportunity to attend training of members of the Immigration and Refugee Board (IRB) on Sexual Orientation and Gender Identity (SOGI) claims and responded to the recent refugee reform bill on behalf of Rainbow Refugee. All of these experiences have informed my understanding of how queer refugees engage with Canada's refugee system and the work of settlement.

The second strategy involved conducting and analyzing in-depth narrative interviews with nine refugee claimants or convention refugees. ${ }^{20}$ My use of narratives as tools for both inquiry and representation was influenced by the constructivist narrative tradition in psychology, ${ }^{21}$ the critical ethnography Impossible Dance, ${ }^{22}$ as well as feminist and queer work in migration studies. ${ }^{23}$ I met with each interview participant up to three times. ${ }^{24}$ In the first one or two meetings I asked participants to share their experience of (1) living in their home country and the events leading up to their leaving, (2) their migration, (3) their application process, and (4) settling into Vancouver. I attended and listened carefully, using open-ended questions, empathic reflections, and probes to invite elaboration. This resulted in two and one-half to six hours of narrative account per participant. I listened to and transcribed interviews using stanzas and episodes, a method designed to closely reflect the form of spoken language. ${ }^{25}$ Participants narrated their experience with emotion, language, and form critical to the meaning, and this listening/transcription process enabled analysis of these aspects of their narratives.

I then conducted several rounds of listening and readings of the transcript, each for a different purpose: a content reading, a dialogical reading, and a critical reading. The content reading focuses the actions of the narrator, situated in interactions and events, that answer the research question how did this person engage in settlement? My use of "engage" in the research question draws attention to the co-actions and active co-constitution of meaning that refugees engage in throughout settlement. I chose this term to reflect the creative, emergent, relational, and socially mediated agencies that refugees bring to the work of settlement. ${ }^{26}$

The dialogical reading draws on Bakhtin's concept of polyphony, or voicing of multiple selves and others, present in the act of narrating. During the interview, as participants recount their memories, they enact past, present, and possible future selves-in-relation to implicitly present others. This reading entails interpreting these many selvesin-relation narrated in recounted events, and in the interview interaction. For this reading, I ask questions like: How are participants narrating themselves? What voice are they using? Who are they interacting with? How are they positioning themselves in relation to these others? to me? What emotions are they embodying as they narrate? What stance are they taking in relation to others? to me? What cultural metanarratives or other voices are they drawing on as resources? I conduct this dialogical reading in an effort to investigate the embodied relationality of participants' engagement in settlement.

The third reading was a critical analysis of the ways in which participants engaged with power in their settlement process. ${ }^{27}$ Examples of questions asked during this reading include: How does the narrator understand and engage with power as it is manifested in social institutions and interactions? What language do they use to speak about social institutions, policies, and laws? Interviews with lawyers and community organizers, the third data generation strategy, helped generate a systems perspective useful in this critical reading. Qualitative analysis software Atlas.ti was used to support this process. ${ }^{28}$

The final stage of analysis involves bringing this systems perspective into dialogue with my own field notes and the narrative interview accounts, to write the research texts. Texts comprise exemplars from interview excerpts and interpretations based on the multiple readings. These texts were then discussed with participants and community partners. Each excerpt presented is a narrative that was told by participants during interviews or, in one case, participantobservation. Interview transcripts were followed closely 
with only minor edits (removing ums, ahhs, and false starts) for ease of reading. The narratives are presented with quotation marks around areas of voiced speech of others or past-selves to highlight the double-voicing of participants' narration. Italics denote voiced self-talk. I interpret areas of double-voicing or voiced self-talk as points of intensified conflict or contact among voiced selves. As well as providing situated accounts of refugees' quotidian efforts to settle, these texts serve as exemplars of participants' dialogical enactments of self-identity in engagement with relations of power. Each exemplar conveys something of participants' embodied negotiation of safety and belonging in engagement with intersectional social exclusions. While highlighting the struggles and efforts of queer refugees, each exemplar speculatively elaborates on relational agencies in participants' negotiations of transnational migration, the refugee system, un/belonging, ${ }^{29}$ and un/settling.

\section{Participants}

The refugees and claimants involved in this research were a very diverse group in terms of sexualities and genders, country of origin, language, age, and socio-economic backgrounds. I make no claims that the Rainbow Refugee participants and interview participants are representative of LGBTQ refugee claimants in Canada more generally, but will provide a sense of who I have worked with to construct this knowledge.

Rainbow Refugee members are predominantly men who identify as gay, bisexual, or queer. Women who identify as lesbian, or queer, and transwomen (male-to-female, mtf) comprise less than a quarter of the membership. The group is diverse ethnoculturally: Spanish speakers from Latin America, Farsi speakers from Iran, and Arabic speakers from Middle Eastern countries are the largest language and cultural groups. The remaining members originate from South Asian, Southeast Asian, and African countries. Because of the focus of the group on the refugee claim process, the vast majority are refugee claimants. A very small number of Government Assisted Refugees, Iranian nationals who made claims at the office of the United Nations High Commissioner on Refugees (UNHCR) in Turkey, have recently tapped into the group for social support and community referrals.

Interview participants were recruited through letters of invitation distributed at Rainbow Refugee meetings and to lawyers who work with LGBTQ refugee claimants. I provide demographic information in aggregate or broad terms in order to protect the identity of participants. I interviewed two transwomen (from two regions: Middle East and Latin America); three queer women (from two regions: Latin America, Middle East); four queer men (from four regions:
East Africa, Southeast Asia, South Asia, and Middle East). They had been in Canada for one and one-half to nine years. All spoke English as their second or third language, although several had completed their education in English. Interpretation was offered if participants wanted to use their first language for interviews. One interview was conducted with an interpreter who was known to the participant and identified as queer. Participants were twenty-five to fortytwo years old. Their socio-economic status in their home countries varied, including rural, poor backgrounds, urban middle-class backgrounds, and urban elite backgrounds. Six participants had some post-secondary education prior to leaving their home countries; of these, three pursued further education in Canada. Two others had pursued, or were in the process of pursuing, post-secondary education in Canada. Eight of nine were employed in jobs that included hotel accountant, warehouse manager, IT specialist, retail sales staff, and business consulting.

\section{Living in Defiance: Persecution, Stigma, and Erasure}

Propelled by fear of violence and flight from stigma, impelled by desire for connection and belonging, the movements of people whose sexualities or genders defy and offend norms cover a complex spatial, social, and psychological terrain. In their home-country accounts, participants told me their stories of living in defiance of homophobia and transphobia in their own cultures, conveying the range and interaction of extreme forms of systemic persecution through more subtle impacts of social erasure and stigma.

In an interview, ${ }^{30}$ Adil, a refugee claimant in his late twenties from one of the Gulf States, told me about how after six years together, his boyfriend wanted to continue a secret relationship while they both started dating women, possibly even married. Adil said his boyfriend was being realistic. When I asked if he knew others who managed this way, Adil explained.

I don't know. I wasn't really in touch with other gay people. I isolated myself ... It was really dangerous to be part of a ... a group. It is really crazy to be part of a group. If something happens to this group, I'm part of them, my name will somehow be out there. I don't want anyone to come to my dad and tell him "your son ..." People know my father and I can't let that happen. I still want to honour my dad. I don't want to bring my name anywhere.

So I was like no ... I don't want to be comfortable, because if I feel comfortable something will happen. Something will definitely happen. It's always like that. So I was always cautious.

Adil looked around wide-eyed, vigilant and fearful. I asked Adil, "How did you figure out that it was dangerous?" 
.... Mmmmm .... the news. On the news "So-and-so was beheaded tonight because he was homosexual.” Isn't that enough?

Policemen harass me because they want something. Like "do me this favour or I'll get you in trouble." I cannot complain. I don't have the right to speak. It's not a place where people can live. You have no rights whatsoever. So what's the point?

So I was always quiet. Keeping myself in-to survive. Dress in a certain way so I won't attract attention. Even walk in a certain way because I don't want attention. Because if I walk the way I walk-people follow me on the street. I don't know who they are: Are they interested? Are they cops? I don't know. Is it a trap? I have no idea.

In Adil's account I heard how official persecution creates the means for abuses of power by police-and others in authority. Portrayals of homophobic violence instill fear, and this fear becomes embodied-constraining movement, enforcing social isolation, and fuelling mistrust of others and self. The ever-present possibility of verbal or physical aggression, something Didier Eribon terms "ambient harassment," shapes the lives of LGBTQ people profoundly and subtly. ${ }^{31}$

In Adil's account I heard how something as basic as how one walks can become a dangerous marker of a persecuted identity. I heard the pervasiveness of the danger-how it seeps into daily life through the surveillance and gossip of neighbours. The possibility of recognition carried fear, shame, and stigma not only for Adil but also his family. The weight of carrying his family name edged him towards conformity. Although this conformity offered some protection, the effort required to sustain this conformity made a livable life impossible.

In an interview Miriam ${ }^{32}$ relayed her experience of searching for similar others and struggling to find a name for her experience.

I remember visiting an internet site for gay men-and they were all muscular, all manly. If they are gay, what am I? I just started to ask myself. I got so confused. I thought I am nothing. I thought $I$ am nothing in this world-not even gay. So what am I?

After that I read an article in the newspaper about transsexuals because they arrested two transsexuals in a nearby city and a journalist interviewed these two transsexuals. A doctor explained about transsexuals, and said "Police, please don't disturb them and don't abuse them. They don't have any fault. They are women. They just need surgery.” Always I knew that I was a woman-but I thought that I was gay. I didn't know.
I was in an internet chat room. Just by accident-I really believe that sometimes the universe helps you--I went to a room for a province, not the city where I am from. I met this guy there. We talked for five, six months and I was so scared "I want to tell you something-a secret-it could destroy us.”

And after I told him, he was so upset. He said, "Why did you think our friendship would be destroyed? I still like you and I will try to help you. You are a woman-not a man. You should not have to hide."

Erasure, the practiced denial of transgressive sexualities and genders, renders livable lives for LGBTQ people invisible. ${ }^{33}$ Here, Miriam voiced her struggle to form an identity under conditions of erasure. Her first encounter with a name for her experience was layered with associations of criminality, and a medical authority specifying a particular intervention. Encountering this narrative of transexuality in the newspaper brought a mix of relief, shame, and fear-she hid the article to prevent her family finding it and recognizing her in it. Reaching out online allowed Miriam a relational space, emotionally intimate but physically removed, for enacting herself as woman. Her online relationship with this man continued and deepened. Eventually, he used his contacts to help her connect with an organization that helps queer asylum seekers.

Participants narrated a sense of isolation in the face of erasure of trans-gendered or queer sexualities. Although many participants grew up in contexts where same-sex sexual activity and gender nonconformity were tacitly tolerated in children and young adolescents, this tolerance gave way to increasing pressure to conform to normative genders and heterosexual life-scripts. Participants narrated difficulties imagining a future self other than the heterosexual life-scripts presented to them-and struggled against hopelessness when their futures seemed bleak. Dominant discourses of sin, deviance, and pathology meant that the primary language available to them was problematic, and located the source of the problem in the individual. Discourses of sin or pathology intensified isolation, and impelled some participants to channel efforts into trying to change themselves. These discourses worked against participants framing their struggle in terms of human rights or social justice issues.

Even under conditions of state persecution and pervasive cultural stigmatization, many participants connected with other queer people or local spaces where queer people congregated. House parties, cafés and pubs known by word of mouth, and chat rooms were places where participants formed relationships and networks. Their accounts highlight some of the tactics, or homing devices, ${ }^{34}$ used to forge 
subaltern networks-personal introductions, private spaces as gathering places or staging grounds, coded language, attunement to subtle nonverbal cues, and sharing stories. Taking the risk of seeking out others broke through isolation, but carried potential risk and shame.

Participants' ability to connect with queer networks, while remaining safe, was complexly and intersectionally constituted. Several participants discussed ways that being part of racialized minorities in their country of origin made them more vulnerable to vigilante violence or surveillance by police. A man from a prominent family in a politically influential religious community constrained his efforts to seek out others, knowing that he would be scrutinized and his family vulnerable to bribery. One woman was targeted by authorities in part because her family members were openly opposed to the governing regime. Engaging in activism on queer, HIV, or labour issues has made some Rainbow Refugee members targets for persecution.

Persevering under conditions of erasure, stigma, and persecution created dialectical tensions between dis/avowing transgressive desires, dis/owning stigmatized identities, seeking out and avoiding similar others, conforming, and escaping in the home country accounts of LGBTQ refugees. The exit and migrations recounted by queer refugees conveyed these dialectic tensions through movement between conforming, and escaping: conforming in order to maintain connections with family, friends, and community; conforming in order to distance themselves from discourses of queer sexualities and genders as pathological, deviant, or immoral; escaping into cafés, and social gatherings known by word of mouth; escaping into secret relationships or online spaces; escaping into bigger cities, tourist enclaves, or overseas. It was not unusual for people to have moved back and forth several times between home towns, to bigger cities, or even other countries, in this dialectic of conformity and escape.

\section{Queer Im/mobilites: Complex, Precarious Migration Trajectories}

Hope mobilizes. The hope of someplace better propels queer migration. Efforts to locate and belong to communities of similar others are prominent features in queer life stories. ${ }^{35}$ Internet chat spaces, gay tourist destinations, and NGO meetings were places where participants encountered LGBTQ people from other countries and learned of possibilities for living their sexualities or genders that existed beyond their national borders. These interimbricated networks of local and transnational LGBTQ cultural sites ${ }^{36}$ provided the hope, and sometimes the means, of mobility.

Migration trajectories of LGBTQ migrants in this study were lengthy-often over many years, complex, and for some precarious. Migrants' mobilities were constrained by the relative obscurity of refugee protection for LGBTQ people in interaction with stringent migration restrictions. Complex migration trajectories became precarious, courting violence, exploitation, or loss of status. Furthermore, complex, mixed migration trajectories are at odds with the expected trajectory of refugee flight of genuine refugees, in which a crisis impels an urgent escape and the potential refugee takes a direct path towards seeking assistance. Any deviations from this trajectory potentially raise questions about credibility and authenticity as refugees in the application process.

In contrast, participants in this study left to avoid danger and escape constant constraint, without necessarily knowing that the dangers they faced constituted persecution. They left with hope for safety and belonging elsewhere, typically without knowing of the option to seek refugee protection. With the exception of Miriam, participants in this study left their home countries unaware of asylum for sexual orientation or gender-identity-based persecution. Several had planned only as far as getting away for a while-hoping that work or study abroad would open up other options. Those who were fleeing imminent danger, left with only a plan to get out by any means possible.

Intersecting asymmetries of gender, social class, race, and nationality constrained if and how participants were able to leave their homes and home countries and cross borders to travel abroad, and who was able to obtain permanent status. In many parts of the world for women and those born female, restrictions on mobility begin at home-with social and legal sanctions against independent travel. ${ }^{37}$ Robert Hughes, a lawyer specializing in queer immigration and refugee law, relayed that lesbian clients from countries with these types of sanctions had often undertaken elaborate and dangerous schemes to obtain travel documents and leave their homes in secrecy. ${ }^{38}$ These restrictions also impact transmen with female travel documents. All of the lesbian and transwomen I interviewed expressed fears for their physical safety while narrating their departures. Among the lesbian women I interviewed, having family already living abroad, travelling with a family member, or having the financial support of family enabled them to leave. The transwomen in this study crossed borders documented as male, fearful that their gender nonconformity would draw intensified scrutiny. Among men in this study, mobility was facilitated by access to education or career. The men had pursued training or work that enabled them to obtain travel documents and cross borders, for example, on board ships, in tourism, or in IT. Uneven access to mobility, produced through the intersectionality of exclusions based on sexuality, gender, 
social class, and nationality, work for and against potential LGBTQ migrants, producing diverse and complex migration trajectories.

To make it to Canada potential claimants must pass through screening measures designed around the prior ities of global capitalism and post-9/11 notions of security. Along with other Western nations, Canada is using increasingly stringent measures to curtail "illegal" migration and to screen out potential asylum seekers. ${ }^{39}$ Ordinary citizens from "refugee producing" nations are usually unable to obtain entry visas into Canada. Those who cannot provide evidence of financial means and substantial ties to their country in the form of property, permanent employment in a profession, or spouses and children typically cannot obtain visas. The Safe Third Country Agreement between Canada and the US has, with some important exceptions, eliminated the possibility of claiming asylum for most people who cross between the two countries at a land border. In Making People Illegal Catherine Dauvergne argues that the punitive effect of these measures on potential refugees is contributing to an increasing illegality of asylum itself. ${ }^{40}$ Navigation of these restrictions is further complicated for those evading homophobia or transphobia in ways that are particular to LGBTQ survival migrants.

The marginalization of queer lives in human rights and refugee discourses worked against refugee protection occurring as a possibility to participants and limited access to the knowledge of the process. Images of refugees as mass movements of people fleeing war meant that participants did not recognize themselves as potential refugees. The fact that homophobia and transphobia can result in persecution was often not apparent to those who experienced it-even in extreme forms. Further, sexual orientation and gender identity are not explicitly named as grounds for protection in the Geneva Convention or Protocol related to refugees. ${ }^{41}$ At the time participants were migrating (prior to 2007) there was no information on LGBTQ asylum apparent on the official websites or literature of the UNHCR. Even now, the visibility of this protection on official sites is limited. It is only since 2007 that sites offering information about LGBTQ asylum have had web presence, much of it in English. ${ }^{42} \mathrm{Web}$ presence alone does not create access given censorship, the unfamiliarity of key words for searching, computer access, and language issues.

Most participants learned of the option to seek refugee protection only after living abroad for some time. They learned of the option through informal, often queer, networks, not official channels. Reaching out online in a chat room connected one man with a LGBTQ community organization, which then connected him with a refugee lawyer; another learned about Rainbow Refugee from a man he met online; friends of a lesbian participant, living out-of-status in the US, located a LGBTQ lawyer and persuaded her to take the chance of seeking help. Queer and social justice networks served as both conduits of contacts and intermediaries of trust, connecting people to the information and people that enabled them to access refugee protection.

For queer migrants, complex migration trajectories also reflect the recalibration of identity that occurs as people meet and participate in new social relationships and communities. Sometimes, it was only after living outside their home countries to work or study, and shedding some of the constraints they had lived with, that people realized the impossibility of their return. For some, living abroad to work or study was their first experience of open, relatively safe, queer communities. These experiences stretched the horizon of the possible for participants-creating an imaginable life, and future, in which they could begin to embody and live their sexuality or gender. In the process of shedding constraints and living more openly as LGBTQ, some were "outed" to family or more publicly, making a return to their country of origin extremely risky. Some who had only explored a LGBTQ identity while abroad chose to return to their home countries with the intention of living discreetly. However, once back home they became targets of threats or violence that forced them to leave once again. These are some of the ways people's identity formation and migration processes mutually shaped each other, creating complex migration trajectories in the process.

Migration restrictions, and the relative obscurity of the option of claiming asylum based on sexuality or gender identity, combine to create situations in which queer migrants pursue more apparent, but sometimes irregular, means of migrating and gaining status. These irregular migration paths placed them in jeopardy of losing their status and were rife for exploitation and violence. Alana, a lesbian from South America, used a heterosexual marriage to attempt to obtain status in the United States. These arrangements were amicable at first, but became coercive over time. It was only after several years that she learned of the option to apply for asylum based on sexual orientation. By this time, she was not eligible to make a claim in the US because the US requires any refugee claim to be filed within a year of entry. Had the Safe Third Country Agreement been in effect when she arrived at a Canadian border, she would not have been eligible to make a refugee claim in Canada. Another queer woman who had been imprisoned and tortured in her country of origin, travelled with agents hired by her parents. These agents sold her into the sex trade en route. She escaped with the help of a client, and was once again reliant on agents to travel to Canada. Two transwomen entered Canada on a temporary visa for work as an exotic dancer, another as a 
live-in caregiver. When work conditions became exploitive, they were forced to decide between remaining under these conditions or losing their legal status. Adil, the young man I quoted earlier, came to Canada on a student visa, while also in a relationship with an American man. The two lived together in Canada with plans to immigrate as a couple. Adil had some confidence that, after graduation, he would have a strong independent application. However, his partner was controlling and became emotionally and physically abusive. Adil's studies suffered, forcing him to leave school. Facing the expiry of his student status, he felt stuck in the abusive relationship. It was only after enduring the abuse for more than a year that he learned about the option to make a refugee claim.

The growing illegality of asylum has dangerous implications for all potential refugees. Migrants in this study courted illegality as a result of exclusions based on intersecting asymmetries of gender, social class, and nationality. These migration restrictions, in interaction with the relative obscurity of the LGBTQ asylum option, placed LGBTQ migrants on mixed or irregular migration paths, creating conditions that increase LGBTQ migrants' vulnerability to exploitation and violence. Having survived the traumas of exclusion from families and communities, and of persecution due to their sexualities or genders, some LGBTQ migrants were then retraumatized by exploitation, and in some cases violence, in the process of migrating. The fact that the migration trajectories of LGBTQ asylum seekers include social, economic, and sometimes irregular means of migration can play into popular criticisms of asylum seekers as "economic migrants," less than genuine, or less deserving, refugees. At the hearing stage, mixed or irregular migration paths can undermine claimants' credibility. Any migration path that deviates from expected trajectories of refugee flight can raise questions about claimants' fears of persecution. Claimants can face additional questioning about delays in departures, transit through other safe countries, or delays in making a claim. However, it is important to recognize that the root cause of the eventual need to claim asylum is the existence of homophobic and transphobic persecution in their home countries. Further, LGBTQ migrants resort to alternative, sometimes irregular, means of migration because the option to make a claim based on sexual orientation or gender identity is not apparent or accessible. These combine to create migration trajectories that do not conform to expectations of refugee flight. Complex negotiations of conformity/escape, the context of erasure of human rights protection for transgressive sexualities and genders in interaction with migration restrictions may make unconventional migration trajectories common.

\section{Making a Claim}

Once at a Canadian border, Citizenship and Immigration office, or UNHCR office, asylum seekers must make their claim to an anonymous officer. One of the first questions they will face is, "On what grounds?" Potential claimants have left contexts of systemic homophobia, where police and officials are precisely the people they fear. One Rainbow Refugee participant, after making his way from Iran to China, Indonesia, Japan, and eventually Canada, spent twenty-seven days in detention before working up the nerve to tell his duty counsel that he was gay.

Rainbow Refugee members have joked about getting t-shirts made with the slogan, "Proud member of a very particular social group." This is a spin on the grounds on which they apply for asylum in Canada. Since 1993, the Geneva Convention criterion of "membership in a particular social group" has been interpreted by the UNHCR, and a Canadian Supreme Court ruling, to include persecuted sexual or gender identities. ${ }^{43}$

A refugee must convince an officer of the Immigration and Refugee Board of the genuineness of their LGBTQ identity, and of their fear of persecution based on that identity. LGBTQ claimants invest considerable effort collecting letters from current or past lovers, friends, or family, recovering medical or police records, assembling photographs, or sifting through newspaper stories, to try to make the hidden visible. Even when documentation is available, a great deal of weight is given to the accounts provided by claimants. ${ }^{44}$ In the application process claimants are asked to provide detailed accounts in the eligibility interview, in their Personal Information Form (PIF), and again in their hearing that consistently corroborate a claim to a highly stigmatized identity. Claimants' safety and survival rely on their intelligibility and recognition as gay, lesbian, bisexual or trans people by the IRB official.

\section{Alana}

After a Rainbow Refugee meeting, four of us went out to toast the successful refugee hearing of Alana, originally from a South American country.

I was so nervous-had terrible nightmares all night. Woke up shaking. I knew I had to look as butch as possible to be sure I looked like a lesbian to the judge. So I pulled back my hair, no make up. Put my baseball cap on sideways, and picked my most classic white shirt. I made sure I sat with my shoulders square and feet planted wide.

As she spoke, Alana's shoulders broadened. She set her jaw and deepened her voice. This petite, long-haired woman 
masculinized before my eyes. It was a way of being of Alana's that I had seen variations of in meetings. ${ }^{45}$

In this conversation, Alana reconstructed her memory of her hearing, invoking the presence of the judge, for an audience of her peers. My use of dialogical analysis informs my attention to the multiple selves and others implicitly present, and voiced, in narratives. With her words and movements Alana enacts her struggle for recognition and credibility. Alana is engaged in a struggle to make herself recognizable to the judge as a "member of the particular social group"lesbian. How well does a North American understanding of same-sex desire as a source of lesbian identity, and of lesbians as masculine, fit with Alana's gender and sexual orientation? What impact does the IRB member's implicit understandings of sexuality and gender have on his ability to recognize and believe Alana?

This interaction gives a sense of how the stories that can be told about being lesbian, or any other LGBTQ identity, are highly proscribed by systems like law, psychology, and medicine-as well as a sense of how people struggle and play with these limits. Alana-narrator is remembering Alananarrated as butch with some amusement, in the process constituting a not-so-butchy lesbian or a lesbian of questionable butchiness. She is engaged in conversation with a group of us who have some understanding of the challenges of navigating people's stereotypes about queer women, and so positions herself as an insider in this group. Where Alana-narrated is in a position of trying to conform to the social discourses of what it means to be a lesbian by Western standards, Alana-narrating is treating the need for that conformity with some irreverence.

There is a tension in how I narrate this interaction, because I want to be careful not to treat gender or sexuality as a voluntary or volitional process. We are born, live in, and form our subjectivity through gendered and sexual practices always already in place. We cannot transcend these practices. And yet I want to convey that there is effortful interpretation and communication at play. Our efforts are mediated by the power of systems of language, law, medicine, and psychology. Yet, our efforts are also creative and at times tactical. ${ }^{46}$

\section{Eleheh}

My lawyer, he wouldn't believe that I'm gay.

S: Your own lawyer?

My own lawyer wouldn't believe I'm gay.

He kept saying, "You can tell me."
And I'm like, "What do you want me to tell you? Like I'm really gay." Like up until today I can't .... I can't believe it.

So it was the lawyer, his intern, and we had a translator, in case. She was [co-national] and she was the worst one. She was so ... like I could tell, she looked like how my mom would be so embarrassed when I'm talking about my sexuality in front of people. She kept looking down, because she was ashamed that I ... like she wasn't happy that I made it, let's just say. And I was so scared of her. What if she goes to the (country-of-origin) embassy and tells them? I was so scared. I was so paranoid.

My lawyer had wanted me to cut my hair short and dress like a man. But I wasn't going to go in there and pretend to be someone I'm not. I went in wearing a skirt and long hair.

The process of preparing for the hearing and the hearing itself places claimants in a web of relationships in which they must be recognized as LGBTQ and as refugee. Eleheh's account gives a sense of how LGBTQ refugee claimants negotiate pressure, subtle and not so subtle, to conform to Western notions of sexual or gender identities. Eleheh rejected her lawyer's advice to conform, and narrated her defiance to me with some pride.

Given the timing of Eleheh's hearing, her lawyer's advice to modify her appearance, as painfully stereotyped as it was, might have been prudent. The Federal Court was hearing a case involving a lesbian refugee claimant. Her "professional" and "attractive" appearance had been used by the board member as a reason that she could return safely and live discreetly $^{47}$. Between 2000 and 2004, Federal Court decisions pointed out the flaws in this line of reasoning. ${ }^{48}$ In 2008 the UNHCR produced a guidance note that advises that SOGI claimants should not be expected to live discreetly. ${ }^{49}$ The guidance note also cautions against expecting claimants to conform to Western stereotypes in appearance. Issues of stereotyping and living discreetly were also addressed in training that IRB members received in 2001, 2004, and 2010. ${ }^{50}$ These measures have reduced, although not eliminated, the chances that claimants will encounter obvious stereotyping.

The accounts of participants with more recent hearings, my own observations of hearings, and the work of legal scholars suggest that the current struggle for claimants in proving the genuineness of their identity claim is more subtle. All refugee decisions are complex, and sexual orientation or gender identity claims are particularly complex. Because of limitations on documentary evidence for both country condition and identity claims, a great deal of weight rests on claimants' testimony. Examining decisions in sexual orientation and gender identity cases, legal scholars 
have shown that the assumptions that IRB members bring about sexual orientation and gender identity reflect popular cultural understandings and Western psychological discourses. ${ }^{51}$ Their research, along with the accounts of LGBTQ asylum seekers in this study, highlights potential pitfalls in the process of telling an identity narrative that is recognized and credible to IRB members. In the high-stakes context of the hearing, LGBTQ refugee claimants' struggle for recognition and credibility is impacted by their own prior experiences of persecution and trauma in interaction with the IRB member's implicit understandings of gender and sexual orientation.

Western psychology has created a view of sexual and gender identity as an intrinsic, essential trait-discovered, expressed, and, once realized, stable. The popularized coming out narrative reinforces this view, and provides an implicit template for identity formation from non-awareness through self-acceptance. IRB members are drawing on their implicit assumptions about LGBTQ sexualities and genders that create expectations of an open claim to a stable identity, and a coherent identity narrative resembling a coming out or gender dysphoria story. However, these narratives are based largely on white Euro-American experiences, and are underpinned by Western understanding of an autonomous self. This culturally encapsulated view of queer sexualities and genders is problematic when assumed to apply more universally. ${ }^{52}$

Both psychological research and the coming out discourse have contributed to a conflation of verbal self-disclosure and open expression of an identity with self-acceptance and stability of an identity. This conflation and the emphasis it places on verbal disclosure have been critiqued by queer studies and psychology scholars, who have highlighted ways that the coming out discourse overlooks tacit, indirect, and nonverbal means of enacting queer sexualities and genders. ${ }^{53}$ Psychological research with diverse LGB populations has demonstrated that acceptance of an identity is not linked with verbal disclosure or openness. ${ }^{54}$

\section{Mzalendo}

It is not an issue that I discuss with anyone, even here.

S: I hear lots of ways it just does not feel safe.

So .... I don't know .... I don't go to bars. I understand there are bars for homosexuals. I don't go .... that's one of the issues that came up in my hearing.

She asked, "Have you done anything to show that you've come out as a homosexual in Vancouver?"
I said, “No, I don't dare. I don't belong to strictly homosexuals. I'm a member of a Church, and without it, I'd be nowhere."

I don't know, that's how I explained it and I think she got it.

Claimants are being asked to give a narrative account of a sexuality or gender identity that they have had limited experience articulating. The impacts of disavowing, denying, or submerging sexualities or genders do not disappear once in Canada. LGBTQ refugee claimants may have extremely limited experience putting their understanding of their sexuality or gender into language. Mzlendo was not connected with Rainbow Refugee during his application, and I met him for the first time at our interview. He informed me that, aside from a psychologist, his lawyer, and the officer at his hearing, I was the only person in Canada with whom he had ever discussed his sexuality. In comparison to interview participants with whom I had a prior relationship through Rainbow Refugee, Mzlendo's narrative of his sexuality was sparse. He frequently used phrasing that distanced himself from a sexual identity claim.

LGBTQ refugee claimants are being asked to make a positive claim to an identity that they may inhabit only uneasily. Arrival in Canada does not eliminate the impacts of discourses of LGBTQ sexualities or genders as pathological, deviant, or immoral. It is not unusual for LGBTQ refugee claimants to refer to their sexuality as "a problem," or to use phrases (being "like that") and intonation that suggest discomfort with identity terms like "gay," "lesbian," or "trans." In hearings vague, evasive, or even pejorative language potentially hurts the credibility of claimants. ${ }^{55}$ Yet, these aspects of identity accounts are better understood as impacts of erasure and problematizing discourses on claimants' ability to speak of their sexuality or gender.

In our interview and in his hearing, Mzlendo may also have been challenged to articulate a bisexual identity in contexts where both homonormative and heteronormative expectations are at work. In the narrative of his Personal Information Form Mzlendo was very clear that although he identifies as bisexual, he was perceived as homosexual and "treated as such" in his country of origin. In contrast, the language he voiced in his hearing account-"I don't belong to strictly homosexuals"-could sound evasive or unclear. Bisexual claimants face the challenge of narrating their experiences in a manner that satisfies expectations of stability and coherence of sexual orientation identity. Available research suggests that the acceptance rate for bisexual claimants (25 per cent) is far lower, than for lesbian (48 per cent) or gay claimants (46 per cent), or claimants generally. ${ }^{56}$ Legal scholars attribute this to the emphasis placed 
on immutability of sexual orientation identity in Canadian refugee jurisprudence.

As reflected in Mzlendo's account, the questions of adjudicators often reflect an expectation that claimants will affiliate with and come out in local queer communities. This expectation reflects implicit assumptions in the coming out narrative that same-sex sexualities or gender variance become the basis of both identity and community. When treated as a universal in hearings, queer refugees can seem not to measure up. In Mzalendo's case the adjudicator understood that appearing in queer venues or participating in community events would jeopardize his belonging in the church he relies on. Mzalendo was able to present compelling documentation of a homophobic assault in his country of origin. He had a letter from his psychologist with whom he had discussed his sexual orientation long before making a refugee claim, and evidence of his church affiliation. The weight of this evidence and Mzlendo's testimony were clearly persuasive. However, the cultural specificity of the coming out narrative of community and the constraints against participation in local LGBTQ communities have not always been recognized by adjudicators. In a recent case, a gay Iranian man's identity claim was found implausible. The adjudicator cited this man's lack of awareness of the meaning of the rainbow flag, and lack of participation in the Pride parade his first year in Canada as evidence against the genuineness of his claim to a gay identity. ${ }^{57}$

Expectations of community participation need to be understood in the social and material contexts of queer refugees' lives. Participating in a local queer community may or may not be a draw or priority for LGBTQ refugees. Participants narrated complex dis/connections with local visible, mainstream LGBTQ communities in Canada. A sense of alignment or identification with local LGBTQ communities was not present for most, particularly when they first arrived. Many participants found the everyday tasks of living in a new country, culture, and language left little energy for locating and participating in queer social spaces. Some participants spoke of not knowing what to look for, experiencing queer communities as unwelcoming because of racism, or isolating due to lack of understanding of refugee experiences. Some narrated feeling alienated or exoticized by the pick-up atmosphere of clubs. Struggling financially, working several part-time jobs, and living on the outskirts of the city also constrained queer refugees' participation in local LGBTQ communities. As Mzlendo's account showed, arrival in Canada is not always enough to create the safety needed to openly participate in local queer community events. The desire to maintain relationships with local co-national or faith groups created fears around participating in local queer community events. It is not unreasonable to ask about queer community participation to evaluate a LGBTQ identity claim but, given the complexity of identifying with, locating, connecting, and participating in local queer communities, community participation should not become a defining criterion.

Although it is the claimant's membership in a persecuted social group that is the basis for the claim, the sexual behaviour of claimants often becomes a key point of evidence in hearings based on sexual orientation. This requirement created a great deal of anxiety prior to and during hearings for participants. Preparing for hearings requires claimants to mentally revisit sexual experiences that were often steeped in intense feelings of shame and fear of being discovered. Prior to hearings participants struggled with the awkwardness of asking past or current lovers for letters or to serve as witnesses. From their hearing experiences, participants described a wide range of approaches to the questioning around sexual behaviour. Infrequent, but most distressing, were pointed questions about sexual experiences, names and contact information of past lovers, or numbers of partners. More often, participants were asked to describe their relationships in their own terms. I have observed IRB members working to convey respect and sensitivity around questioning on sexual relationships.

The hearing process often implicitly fuses an LGB sexual identity with sexual behaviour, and may place undue weight on the sexual behaviour of claimants. This sexualization of LGBTQ identities is attributable in part to the impact of heterosexist discourses of deviance. Claimants with limited sexual experience are at a disadvantage, and the emphasis placed on sexual relationships in hearings has worked against queer claimants. ${ }^{58}$ Alvaro Orozco, a young man from Nicaragua, lost his refugee claim in 2007. The adjudicator in this case did not find his claim to be a gay man credible, in part because he had not taken the opportunity to have sexual relationships while residing in the US. ${ }^{59}$ Surfacing and critiquing these assumptions is important to ensuring a fair hearing process for claimants.

All queer claimants are working with and against culturally proscribed identity narratives in their hearings. For participants in this study who filed claims based on sexual orientation, the struggle entailed making the hidden, or invisible, visible to adjudicators. Those who claimed based on gender identity faced a slightly different struggle. For the two transwomen in this study, the challenge at the hearing was to make the inconsistencies in gender accounts coherent to the conventionally gendered. Trans claimants worked against the perceptual and imaginal limits created by discourses of binary gender to help decision makers comprehend the daily realities of living transgendered. 


\section{Miriam}

And three months later, I got the letter from the Canadian Embassy that they want me for an interview. I went there and had another interview with a worker and I had a translator. And still .... he repeated the same question as the other officer.

"I can't believe it. How you could \{checks in with interpreter\}

Int: fool f-o-o-1

"How could you fool your family? You say you had problems outside, but when you are at your place your family didn't know you were transsexual?"

I said "My family had been living with me for years and years and years. My family had seen me for years; how I walk, how I talk. But when I go somewhere to apply for a job and I say Salam, they say "Why does he talk like a woman?" It was very noticeable.

Officials at the UNHCR and Canadian Embassy readily perceived Miriam as transgender: her dress, mannerisms, and speech all conveyed femininity to them. For Miriam, the issue of credibility manifested as officials repeatedly questioned the seeming contradiction of living without her family "knowing," while also experiencing public harassment. Miriam struggled to convey the tacit tolerance of her gender fluidity within her family. In contrast, in official contexts-school, university, and work-Miriam encountered open, sometimes violent, objections to her gender nonconformity. As she narrated her application process, Miriam recounted multiple events from her past to try to make this complexity imaginable to officials. Later in the interview, Miriam described to me how in her home country "the distance between transgender and straight is not as large as in the West." Miriam worked to convey, in her hearings and our interview, the complexity that allows the coexistence of extreme forms of official persecution with relational acceptance of gender fluidity.

\section{Stephanie}

The thing is the hearing. It was really rough because the attitude of the person was ... was different. This person was not familiar with transsexuality. I could tell. The way this board member asked questions was so direct. He was very rude.

\section{S: Are you comfortable giving some examples?}

He asked me about my parents, and he asked me "When you were in (country of origin) what did you do?"

"I worked with my father. He had a mechanics shop." I told him.
And he said, "Ok, when you were a man, and you were working as a man. And he asked, "When you were in [country of origin] were you looking for a job? Are you educated?”

He was attacking me very directly on this point. He tried to imply that I came to Canada just to have the surgery. He was talking very fast, and it was hard. I asked for a translator even though I speak English. There was a point where I was totally upset with this guy.

He said "How can you say to me that your life is in risk in [country of origin], when I have here some evidence that says that the laws are changing, and you have better ways to be protected?"

At that point, I was like, "I don't want to seem rude, but have you ever been in [country of origin]?"

He said "No."

"Would you be brave enough to go to [country of origin] dressed in a skirt? Would you be able to do that?"

S: Good for you. What did he say?

He reserved his answer. He didn’t say anything.

S: I hear how the whole experience really rattled you.

I finished feeling like I had been to battle. I felt like I was under attack, rather than under .... than being listened to. At the beginning he was very nice, very nice, and I was yeah I'm feeling comfortable. But then as time passed he started getting rude. At the beginning, he was like,

"There is no problem with the identity of this person. It's clear this person is transsexual."

He didn't have any doubts about me being transsexual. I mean right in his hands, he had the affidavit that I had passed through the surgery. He didn't have any problem with that, so he had to go for something else.

Stephanie had felt respected during her interactions with immigration officials early in her application when they addressed her as "Madame" or "Ms." and avoided using the male first name on her documentation. She contrasted these early experiences of recognition with her hearing. Her anger came through as she voiced her memory of the board member's emphatic repetition of "as a man." Having never lived straightforwardly "as a man," the phrase distorted her understanding of herself and communicated disregard for her as a transwoman. In our interview, Stephanie located the problem firmly with the board member's lack of understanding of transexuality and trans genders. Where Stephanie-narrated felt increasingly nervous, desperate, and 
under attack, Stephanie-narrating was assured and clear that the problem lay with the board member. In reenacting her hearing Stephanie voiced confronting the board member-pointing out his lack of familiarity with the situation for transwomen in her home country, and simultaneously trying to evoke an empathic response. Could he imaginally experience, even momentarily, the threat entailed in transgressing gender?

Questions of identity are usually addressed first in refugee hearings. For Stephanie, the documentation she was able to provide from doctors and psychologists clearly left no need, or room, to question her identity. Stephanie connected with a support group for transgender people during her waiting period, where she met trans others, and began exploring surgical options for continuing her transition. Working her way through the assessment process for these procedures provided evidence corroborating her trans identity that the board member readily recognized and accepted. In this way, Stephanie had done the work of gaining official recognition prior to her hearing.

Stephanie-narrating understood how the certainty of her identity, recognized by medical authority, shaped questioning during the hearing. Without questions of identity as a reason for exclusion, the board member raised questions of credibility and authenticity as a refugee. Her account of the hearing suggests that a trans-specific version of the economic-migrant-as-bogus-refugee discourse may have been at work. Stephanie worked against being positioned as such in the hearing, and in our interview. She repeatedly emphasized that she started working, paying taxes, and paying her own Medical Service Plan payments as soon as she was able.

Documenting and providing testimony about sexual or gender identities formed under conditions of persecution requires claimants to revisit traumatic events steeped in shame. Pervasive homophobia and transphobia exacerbate the potential for sexual violence, coercion, and exploitation. Among participants I interviewed, most had experienced actual or threatened sexual violence, and several had experienced coercion within sexual relationships. Interpersonal violence in the form of assaults by family members, classmates, and wider community members were recounted by most interview participants, and are common experiences among members of Rainbow Refugee. One participant had been imprisoned and tortured.

The relational betrayal that occurs with homophobic or transphobic assaults and sexual violence, and complex trauma histories associated with SOGI persecution, are precisely the conditions that undermine claimants ability to produce a coherent narrative.

The fact that trauma can impact claimants' ability to provide a coherent narrative is well established. ${ }^{60}$ Psychological research on trauma, depression, and episodic memory-the form of memory principally drawn on while relaying past experiences-has demonstrated clear effects of depression and heightened emotional arousal on memory encoding and retrieval. ${ }^{61}$ Heightened emotional arousal during a fear response impacts memory encoding such that sensory elements are emphasized, and the narrative flow is often lost. Trauma narratives produced in therapy are often fragmented until therapeutic work enables survivors to reconstruct an integrated memory. Emotional distancing and numbing is a common coping response-producing a very flat affect while recounting traumatic incidents. Ongoing depressed mood results in vague, overly general personal narratives. ${ }^{62}$

Perhaps more so than any other type of claim, SOGI claimants are being asked to recount events steeped in shame that are intertwined with a stigmatized identity. Adjudicators may or may not have awareness and sensitivity to the subtler impacts of mental state on a claimant's capability to produce a coherent narrative. ${ }^{63}$ Formal guidelines exist for claimants identified as vulnerable, providing for procedural accommodations designed to increase fairness, while decreasing the potential for retraumatization. Rousseau and collegues analysis of transcripts suggest that IRB members' defensive responses to trauma narratives can have counterproductive effects on hearings. ${ }^{64}$ I have witnessed a wide range of approaches to eliciting and responding to the trauma narratives of SOGI claimants: some deeply sensitive, some coolly bureaucratic, and some brusque and suspicious. Under new legislation to be implemented over the next year, claimants will be interviewed at fifteen days, providing little opportunity for the assessments required to determine appropriate procedural accommodations.

The efforts of LGBTQ people to create safety and belonging propel them out of contexts of persecution and towards potential places of belonging. LGBTQ asylum seekers have worked against forces of erasure that hide the possibilities and means for living with safety and rights. Leaving without awareness of refugee protection based on sexual orientation or gender identity, queer migrants pursued more apparent migration means. While on these mixed migration paths, the relative obscurity of the asylum option for LGBTQ migrants, in interaction with migration restrictions, placed LGBTQ asylum seekers on trajectories that created the potential for exploitation, violence, or a slide into "illegal" status. The recalibrations of identity that occur as migration brings people into interaction with new social networks and communities further contribute to complicated and extended migration trajectories. The paths of queer migrants in this study did not conform to expected paths of refugee flight. In their struggle for recognition and 
credibility in the hearing process LGBTQ claimants are working with and against highly constrained, culturally situated identity narratives as they recount often traumatic experiences.

\section{Implication and Limitations}

The larger research project from which this work is drawn was designed to explore LGBTQ refugees engagement in settlement. Recognizing that potential for safety and belonging during settlement is conditioned by experiences of persecution, migration, and the application, I asked participants to recount these experiences. Findings regarding the migration trajectories and engagement with the refugee determination process presented here are therefore tentative.

Findings regarding migration trajectories must be understood in the context of the timeframe of the study. The potential points of access to information about refugee protection for homophobic or transphobic persecution have increased markedly since 2007. LGBT asylum advocacy groups now have an online presence. International LGBTQ organizations are working to create greater safety and access to protection for asylum seekers overseas. In Ontario and BC, all refugee claimants are now provided with a resource list that includes local LGBTQ refugee support groups at the conclusion of the eligibility interview. In BC this was implemented through First Contact, a Red Cross project that has the participation of Citizenship and Immigration Canada, the Canada Border Service Association, and a large number of NGOs including Rainbow Refugee. All of these changes potentially create greater visibility and access to information about refugee protection for those facing homophobic or transphobic persecution. A study design focused on migration trajectories that examines the migration trajectories of a broader range of queer survival migrants, and looks specifically at recent migrants, would allow more in-depth exploration of the issue of access to protection.

Juxtaposing detailed narratives with problems identified in existing literature and cases helped identify some of the discourses that implicitly shape refugee determination for LGBTQ claimants. Presenting participants' accounts and our joint interpretation gives a sense of how some claimants have negotiated the struggle for credibility that occurs in the hearing. A dialogical understanding of this struggle highlights the relational and mediated agencies queer migrants bring to their engagements with the refugee system. However, this analysis does not constitute evidence of the pervasiveness or impact of these assumptions. A study design that focuses on the application process, and incorporates written refugee decisions of both positive and negative cases, would allow more in-depth exploration.
All refugee decisions are complex, and SOGI claims are some of the most challenging for adjudicators. ${ }^{65}$ The decision-making responsibilities IRB members hold are enormous, and these narratives convey only some of the complexities and pressures board members face. I highlighted some of the assumptions that undermine fair decision making in hopes that future training with decision makers will address these more subtle assumptions. Canada is, at present, the only country to provide training for decision makers that focuses on SOGI decisions. In the most recent training, legal and human rights perspectives were well presented. Effective training on SOGI decisions would also give adjudicators an opportunity to surface and reflect on the implicit, often culturally encapsulated, assumptions they may bring about queer sexualities and trans genders. Bridging intercultural understandings of transgressive sexualitites and genders would enhance fairness in refugee hearings. Perspectives grounded in the lives of queer refugees, that reflect the social, psychological, and spatial complexities of their experiences, would enhance this aspect of the training.

Advocating and researching with queer refugees in the contexts of Canadian and transnational migration systems as well as the local and globalizing LGBTQ rights movements entails inherent tensions and risks. I highlight these here, acknowledge that my exploration of these tensions was limited in this paper, and offer that upcoming work explores these tensions more fully. At a time when asylum rights are in jeopardy internationally, and migration restrictions are producing people as "illegals," what does it mean to extend refugee protection to those facing sexual orientation or gender identity based persecution? The challenges of accessing the right to safety are myriad for all survival migrants, particularly those in the Global South, and in particular ways for queer survival migrants. This paper focused on the particular challenges of queer refugees negotiating two discourses present in the refugee determination system. This focus speaks to only one part of the much larger agenda and series of challenges that exists for research and advocacy on queer migration.

Post-colonial critiques of queer liberalism and homonationalism ${ }^{66}$ raise further challenges for those of us who advocate and research with queer refugees: how to write about persecution without othering cultures or countries as monolithically homophobic; how to write about the shifts and realignments in identity that occur with migration, without reproducing a transnational version of the coming out story; how to ensure access to refugee protection for those facing homophobic or transphobic persecution, without reifying Western identity categories; how to represent the traumas that occur under persecution and precarious 
migration without fuelling a politics of rescue. ${ }^{67}$ Meeting these challenges will require alliance building, interdisciplinary scholarship, and critical reflexivity in advocacy and research on queer migration.

\section{Notes}

1. Donald Ottoson, State-Sponsored Homophobia: A World Survey of Laws Prohibiting Same Sex Activity between Consenting Adults (Stockholm: International Lesbian and Gay Association, 2009), 4-8, http://www.ilga.org/news _results.asp?/.

2. Amnesty International, Love, Hate and the Law: Decriminalizing Homosexuality (London: Amnesty International Secretariat, 2008), 68, http://www.amnesty .org/en/library/info.

3. LEGIT: Canadian Immigration for Same-sex Partners, http://www.legit.ca.

4. Eithne Luibheid, "Queer/Migration: An Unruly Body of Scholarship," in "Queer/Migration," ed. Eithne Luibheid, special issue, GLQ: A Journal of Lesbian and Gay Studies 14, no. 2-3 (2008): 168-90.

5. Martin F. Manalansan, "Queer Intersections: Sexuality and Gender in Migration Studies," International Migration Review 40, no. 1 (2006): 224-49.

6. Eithne Luibheid, "Sexuality, Migration and the Shifting Line between Legal and Illegal Status," in "Queer/Migration," ed. Eithne Luibheid, special issue, GLQ: A Journal of Lesbian and Gay Studies 14, no. 2-3 (2008): 289-315.

7. Mimi Sheller and John Urry," The New Mobilities Paradigm," Environment and Planning A 38, no. 2 (2006): 207-26.

8. Cindy Patton and Benigno Sanchez-Eppler, eds., Queer Diasporas (Durham: Duke University Press, 2000).

9. Kath Weston, Long Slow Burn: Sexuality and Social Science (New York: Routledge, 1998); Didier Eribon, Insult and the Making of the Gay Self, trans. Michael Lucey; ed. Michele Aina Barale, Jonathan Goldberg, Michael Moon, and Eve Kosofsky Sedgwick (Durham: Duke University Press, 2004).

10. David Valentine, Imagining Transgender: An Ethnography of a Category (Durham: Duke University Press, 2007).

11. V. Munoz, "Towards a Decolonizing Transgender Psychology" (paper, Spring Colloqium on Feminist, Gender and Sexuality Studies, Cornell University, February 29, 2008), http://aurora.wells.edu/ vim/ (cited with permission).

12. Ibid.

13. W. L. Leap and T. Boellstorff, eds., Speaking in Queer Tongues: Globalization and Gay Language (Chicago: University of Illinois Press, 2004); John C. Hawley, Postcolonial, Queer: Theoretical Intersections (Albany: State University of New York Press, 2001).

14. Michael Warner, cover of Queer Diasporas, ed. Patton and Sanchez-Eppler.

15. Patton and Sanchez-Eppler, eds., 3.
16. W. L. Leap and T. Boellstorff, eds., Speaking in Queer Tongues: Globalization and Gay Language (Chicago: University of Illinois Press, 2004); John C. Hawley, Postcolonial, Queer: Theoretical Intersections (Albany: State University of New York Press, 2001); Jennifer Petzen, "Home or Homelike Turkish Queers in Berlin," Space and Culture 7 (2004): 20-32.

17. Anne-Marie Fortier, "Coming Home: Queer Migrations and Multiple Evocations of Home," European Journal of Cultural Studies 4, no. 4 (2001): 405.

18. Manalansan.

19. P. F. Carspecken, Critical Ethnography in Educational Research: A Theoretical and Practical Guide (New York: Routledge, 1996); D. Georgiou and P. F. Carspecken, "Critical Ethnography and Ecological Psychology: Conceptual and Empirical Explorations," Qualitative Inquiry 8, no. 6 (2002): 688-706.

20. Marla J. Arvay, "Putting the Heart Back into Human Science Research," in Studies in Meaning: Exploring Constructivist Psychology, ed. J. D. Raskin and S. K. Bridges (New York: Pace University Press, 2003), 201-24.

21. Ibid.

22. Fiona Buckland, Impossible Dance: Club Culture and Queer World Making (Middletown, CT: Wesleyan University Press, 2002), 242.

23. Isabel Dyck and Arlene Tigar McLaren, "Telling It Like It Is? Constructing Accounts of Settlement with Immigrant and Refugee Women in Canada," Gender, Place \& Culture: A Journal of Feminist Geography 11, no. 4 (2004): 513-34; Martin F. Manalansan, "Diasporic Deviants/Divas: How Filipino Gay Tranmigrants 'Play with the World," in Queer Diasporas, ed. Patton and Sanchez-Eppler, 183-203.

24. Informed consent was discussed in the first meeting and revisited. The final meeting was used to discuss themes found in the narratives.

25. J. P. Gee, "Units of Production of Narrative Discourse," Discourse Processes 9 (1986): 391-422.

26. K. Gergen, Relational Being (New York: Oxford University Press, 2009); J. V. Wertsch, Voices of the Mind: A Sociocultural Approach to Mediated Action (Cambridge, MA: Harvard University Press, 1991).

27. Marla J. Arvay, "Putting the Heart Back into Human Science Research," in Studies in Meaning: Exploring Constructivist Psychology, ed. J. D. Raskin and S. K. Bridges (New York: Pace University Press, 2003), 201-24.

28. Atlas.ti: the knowledge workbench, http://www.atlasti.com.

29. Mary Bryson, Lori MacIntosh, Sharalyn Jordan, and Hui Ling Lin, "Virtually Queer? Homing Devices Mobility and Un/Belongings," Canadian Journal of Communications 31, no. 4 (2006); 791-814; Elspeth Probyn, Outside Belongings (London: Routledge, 1996); Anne-Marie Fortier, "Re-Membering Places and the Performance of Belonging(s)," Theory, Culture \& Society 16, no. 2 (1999): $41-64$. 
30. Adil, interview by author, Vancouver, BC, June 28, 2008. Adil is a pseudonym used to protect the confidentiality of the interview participant.

31. Eribon, 446.

32. Miriam, interview with author, Vancouver, BC, June 15, 2009. Miriam is a pseudonym used to protect the confidentiality of the participant.

33. Eribon, 46; Vivian K. Namaste, Invisible Lives: The Erasure of Transexual and Transgendered People (Chicago: University of Chicago Press, 2000).

34. Bryson, MacIntosh, Jordan, and Lin.

35. Ibid.; Fortier, "Coming Home," 405.

36. Patton and Sanchez-Eppler, eds.

37. National Center for Lesbian Rights, Challenges to Successful Lesbian Asylum Claims (San Fransisco: National Center for Lesbian Rights, 2007), http://www.nclrights .org/site/DocServer/challenges_lesbian_asylum_cases .pdf?(accessed September 28, 2009).

38. Robert Hughes, interview with author, Vancouver, BC, October 30, 2008.

39. Catherine Dauvergne, Making People Illegal: What Globalization Means for Migration and Law (New York: Cambridge University Press, 2008).

40. Ibid.

41. United Nations High Commission on Refuges, Convention relating to the Status of Refugees, 28 July 1951, 189 U.N.T.S. 150; UNHCR, Protocol relating to the Status of Refugees, 4 October 1967, 606 U.N.T.S. 267, http://www .refugeelawreader.org/c/52/I.2.2_The_Universal_Standard.

42. An example is http://www.gayswithoutborders.com that launched in 2007.

43. Nicole LaViolette, "Gender-Related Refugee Claims: Expanding the Scope of the Canadian Guidelines," International Journal of Refugee Law 19, no. 2 (2007): 1-47; Nicole LaViolette, "An Analysis of the UNHCRs Guidance Note on Refugee Claims Relating to Sexual Orientation and Gender Identity," American Society of International Law 10 (2009), http://www.asil.org/ insights090730.cfm.

44. Laurie Berg and Jenni Millbank, "Constructing the Personal Narratives of Lesbian, Gay and Bisexual Asylum Claimants," Journal of Refugee Studies 22, no. 1 (2009).

45. Alana, conversation with author; November 2006; interview with author, April 28, 2009. Alana is a pseudonym used to protect the confidentiality of the participant. This narrative is not a direct quote, but a remembered conversation from field research, discussed in the interview.

46. Patton and Sanchez-Eppler, eds., 5-8.

47. LaViolette, "Gender-Related Refugee Claims"; Sean Rehaag, "Patrolling the Borders of Sexual Orientation: Bisexual Refugee Claims in Canada," McGill Law Journal 53, no. 1 (2008): 59-102.

48. Nicole LaViolette, "Independent Human Rights Documentation and Sexual Minorities: An Ongoing Challenge for the Canadian Refugee Determination
Process," International Journal of Human Rights 13, no. 2-3 (2009): 437-76.

49. "Guidance Note on Refugee Claims Relation to Sexual Orientation and Gender Identity," United Nations High Commissioner for Refugees (UNHCR), November 21, 2008.

50. Robert Hughes, interview with author, Vancouver, BC, October 30, 2008; Observation, training workshop, Vancouver, BC, May 6, 2010.

51. Berg and Millbank; Rehaag.

52. M. A. Fukayama and A. D. Ferguson, "Lesbian, Gay, and Bisexual People of Color: Understanding Cultural Complexity and Managing Multiple Oppressions," in Handbook of Counseling and Psychotherapy with Lesbian, Gay and Bisexual Clients, ed. R. M. Perez, K. A. DeBord, and K. J. Bieschke (Washington, DC: American Psychological Association, 2000), 81-105; L. A. Peplau and L. D. Garnets, "A New Paradigm for Understanding Women's Sexuality and Sexual Orientation," Journal of Social Issues 56, no. 2 (2000): 329-50.

53. Carlos Ulises Decena, "Tacit Subjects", in "Queer/ Migration," ed. Eithne Luibheid, GLQ: A Journal of Lesbian and Gay Studies 14, no. 2-3 (2008): 339-360.

54. Ruth E. Fassinger and S. R. McCarn, "Revisioning Sexual Minority Identity Formation: A New Model of Lesbian Identity and Its Implications for Counseling and Research," Counseling Psychologist 24, no. 3 (1996): 508-34; R. E. Fassinger and B. Miller, "Validation of an Inclusive Model of Sexual Minority Identity Formation on a Sample of Gay Men," Journal of Homosexuality 32, no. 2 (1996): 53-78. Jonathan Mohr and R. E. Fassinger, "Measuring Dimensions of Lesbian and Gay Male Experience," Measurement and Evaluation in Counselling and Development 33 (2000): 66-90.

55. Berg and Millbank.

56. Rehaag.

57. N. Barsotti, “Gay Iranian faces deportation," Xtra West (May 20, 2010), http://www.xtra.ca/public/Vancouver/ Gay_Iranian_faces_deportation-8674.aspx provides a public record of this decision. Final quote reading "the best approach" attributed to me in article is a slight misquote. I said "a better approach ... but even this has problems ..."

58. Ibid.

59. R. Salerno, "Toronto Youth Facing Deportation Tells His Story," Xtra (August 30, 2007), http://www.xtra .ca/public/viewstory.aspx?AFF_TYPE $=1 \&$ STORY_ID $=3549 \&$ PUB_TEMPLATE_ID $=2$

60. Janet Cleveland, "The Guideline on Procedures with Respect to Vulnerable Persons Appearing Before the Immigration and Refugee Board of Canada: A Critical Overview," Refuge 25 (2008).

61. Bessel A. van der Kolk, "Trauma and Memory," Psychiatry and Clinical Neurosciences 52, no. 5 (1998): 97-109.

62. Ineke Wessel, Masja Meeren, Frenk Peeters, Arnoud Arntz, and Harald Merckelbach, "Correlates of Autobiographical 
Memory Specificity: The Role of Depression, Anxiety and Childhood Trauma," Behaviour Research and Therapy 39, no. 4 (2001): 409-21.

63. Berg and Millbank.

64. C. Rousseau, F. Crepeau, P. Foxem, and F. Houle, "The Complexity of Determining Refugeehood: A Multidisciplinary Analysis of the Decision-Making Process of the Canadian Immigration and Refugee Board," Journal of Refugee Studies 15, no. 1 (2002): 43-70.

65. Jasbir Puar, Terrorist Assemblages (Durham, NC: Duke University Press).

66. Ibid.

67. Ibid.

Sharalyn R. Jordan is SSHRC Canadian Graduate. Scholar and PhD candidate in counselling psychology at the University of British Columbia. In addition to community service and advocacy on queer migration with LEGIT and Rainbow Refugee, she engages in clinical practice, research, teaching, and training that explores interconnections of mental health and social justice.

The author gratefully acknowledges the contribution to this research by community partners Rainbow Refugee Committee, Vancouver, BC, and by participants who contributed their experience and ideas, and Nicki K. for her skillful interpretation. This piece draws on dissertation research in progress, and the author acknowledges Drs. Marla (Arvay) Buchanan, Mary Bryson, and Cindy Patton for their intellectual and research guidance. 